\title{
Celecoxib reverses the glioblastoma chemo-resistance to temozolomide through mitochondrial metabolism
}

\author{
Delong Yin ${ }^{1, *}$, Guoqing Jin ${ }^{2,}{ }^{,}$, Hong He ${ }^{3}$, Wei Zhou ${ }^{1}$, Zhenbo Fan ${ }^{1}$, Chen Gong ${ }^{4}$, Jing Zhao ${ }^{4}$, \\ Huihua Xiong ${ }^{4}$
}

${ }^{1}$ Department of Orthopaedics, The Third Affiliated Hospital of Guangzhou Medical University, Guangzhou 510150, China

${ }^{2}$ Department of Intensive Care Unit, The Third Affiliated Hospital of Guangzhou Medical University, Guangzhou 510150, China

${ }^{3}$ Department of Obstetrics and Gynecology, Key Laboratory for Major Obstetric Diseases of Guangdong Province, The Third Affiliated Hospital of Guangzhou Medical University, Guangzhou 510150, China

${ }^{4}$ Department of Oncology, Tongji Hospital, Tongji Medical College, Huazhong University of Science and

Technology, Wuhan 430030, China

*Equal contribution

Correspondence to: Jing Zhao, Huihua Xiong; email: zhaojingdoc@sina.com, https://orcid.org/0000-0002-0092-7688; xionghuihua@hotmail.com, https://orcid.org/0000-0002-7752-5724

Keywords: glioblastoma, chemo-resistance, temozolomide, mitochondrial metabolism, cyclooxygenase-2

Received: May 2, $2021 \quad$ Accepted: July 1, 2021

Published: September 8, 2021

Copyright: (c) 2021 Yin et al. This is an open access article distributed under the terms of the Creative Commons Attribution License (CC BY 3.0), which permits unrestricted use, distribution, and reproduction in any medium, provided the original author and source are credited.

\begin{abstract}
Temozolomide (TMZ) is used for the treatment of high-grade gliomas. Acquired chemoresistance is a serious limitation to the therapy with more than $\mathbf{9 0 \%}$ of recurrent gliomas showing little response to a second line of chemotherapy. Therefore, it is necessary to explore an alternative strategy to enhance the sensitivity of glioblastoma (GBM) to TMZ in neuro-oncology. Celecoxib is well known and widely used in anti-inflammatory and analgesic. Cyclooxygenase-2 (COX-2) expression has been linked to the prognosis, angiogenesis, and radiation sensitivity of many malignancies such as primitive neuroectodermal tumor and advanced melanoma. The objective of this study was to explore the chemotherapy-sensitizing effect of celecoxib on TMZ in GBM cells and its potential mechanisms. From the study, we found that the combination therapy (TMZ 250uM+celecoxib 30uM) showed excellent inhibitory effect to the GBM, the LN229 and LN18, which were the TMZ resistant GBM cell lines. Our data suggest that the combination therapy may inhibits cell proliferation, increases apoptosis, and increases the autophagy on LN229 and LN18. The potential molecular mechanisms were related to mitochondrial metabolism and respiratory chain inhibition.
\end{abstract}

\section{INTRODUCTION}

GBM is an aggressive and prevalent brain tumor of the astrocytic lineage characterized as a high-grade tumor of the central nervous system [1]. The median overall survival for patients with GBM is between 12 to 15 months. The standard treatment for GBM consists of tumor removal followed by radiotherapy with concurrent and adjuvant TMZ [2]. Although TMZ is commonly used in the adjunctive treatment of gliomas and can efficiently inhibit proliferation and induce apoptosis of GBM cells, the prognosis of GBM remains poor [3]. Chemotherapy becomes impaired by development of chemo-resistance, especially for the patients with GBM who are frequently exhibited an early deterioration of performance status [4], with the 5year survival rate of just $9 \%$ [5]. This phenomenon presents the most challenging barrier in the successful treatment of GBM and is the principal reason for chemotherapy failure $[2,6]$. 
GBM chemo-resistance includes congenital and acquired resistance, and the acquired chemo-resistance is more serious. More than $90 \%$ of patients with recurrent gliomas have acquired chemo-resistance showing little response to a second line of chemotherapy [7]. Therefore, it is urgently needed to find a strategy to enhance the sensitivity of TMZ in the treatment of GBM patients.

Cyclooxygenase-2 (COX-2) expression has been linked to the prognosis, angiogenesis and radiation sensitivity of many malignancies. Joki et al. [8] have reported that treatment with a COX-2 inhibitor, NS-398, reduced tumor cell migration and proliferation and increased apoptosis in mice bearing xenografts of U-87MG and U-251MG glioma cell lines. And COX-2 protein has been noted in greater amounts in high-grade gliomas than in low-grade gliomas or normal brain, it also shows a link of poorer survival in patients with malignant gliomas that have increased COX-2 expression [9]. Celecoxib is a selected COX-2 inhibitor, which has been evaluated the effect on GBM radiotherapy [10]. Although this study did not get the expected results, it provided important preliminary data and set the stage for future trials evaluating combination therapy with radiation, TMZ, and celecoxib in those patient population. This study focuses on the reversal effect and potential mechanism of celecoxib on TMZ resistance in glioma.

\section{RESULTS}

Low concentrations of celecoxib did not influence the proliferation of GBM cells but enhanced the anti-proliferation of TMZ

The GBM cell lines, LN229 and LN18, were resistant to TMZ treatment had been reported [11-13]. In our

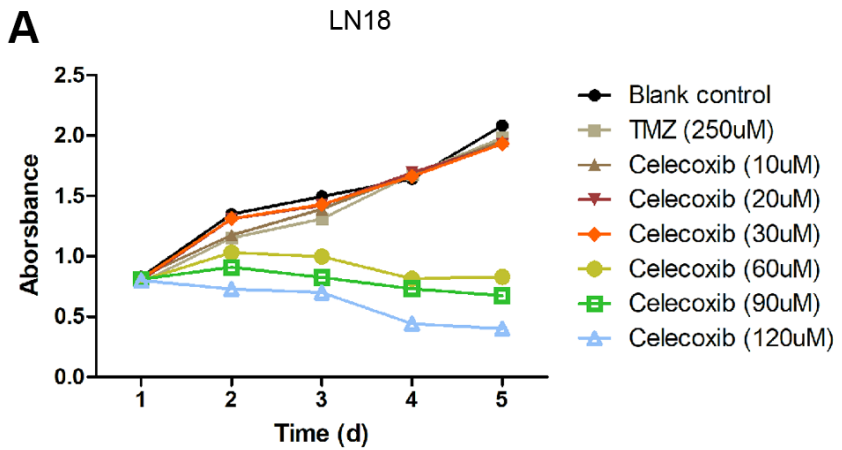

study, we selected these two cell lines to perform cytotoxicity assay with MTS. The LN229 and LN18 cells were treated with celecoxib with $10 \mathrm{uM}, 20 \mathrm{uM}$, $30 \mathrm{uM}, 60 \mathrm{uM}, 90 \mathrm{uM}, 120 \mathrm{uM}$ and $\mathrm{TMZ} 250 \mathrm{uM}$ independently, then we add the MTS to test the cell cytotoxicity / proliferation. The results showed that both cell lines were resistant to $250 \mathrm{uM} \mathrm{TMZ}$ from D1 to D5, and not significantly inhibited by $30 \mathrm{uM}$ of celecoxib. But when the celecoxib dose up to $60 \mathrm{uM}$ and more, the LN18 cell line was inhibited at D2. The LN229 cell line was also inhibited at the same dose of celecoxib but was later than LN18, when the LN229 was treated with celecoxib dose up to $60 \mathrm{uM}$ and more at D3 (Supplementary Table 1 for specific data), these results were consistent with previous research $[14,15]$. Both LN18 and LN229 cell lines were resistant to the TMZ, which were also consistent with the results of previous studies $[11,12]$, the $60 \mathrm{uM}$ and more dose of celecoxib has obvious inhibitory effect on LN18 and LN229 proliferation at D2 or D3 (Figure 1A, 1B and Supplementary Table 1). Then we treated the LN229 and LN18 cells with the TMZ, celecoxib and combination, the MTS assay results showed that the LN229 and LN18 cell line were obviously suppressed with TMZ 250uM+celecoxib 30uM (Figure 2A, 2B and Supplementary Table 2). Yamaguchi et al. [16]. recently reported that celecoxib could play a role in anti-tumor effects in GBM, and our results found that celecoxib may have a chemo-sensitization effect on TMZ. Neither TMZ 250uM nor celecoxib 30uM can restrict cell proliferation, but the combination therapy suppressed the cell proliferation on D2 for LN18 and D3 for LN229, especially in the comparison of TMZ and combination therapy (Supplementary Table 2). Because celecoxib is used as a sensitization drug, rather than a treatment drug, we chose $30 \mathrm{uM}$ as the working concentration that was used for subsequent experiments.

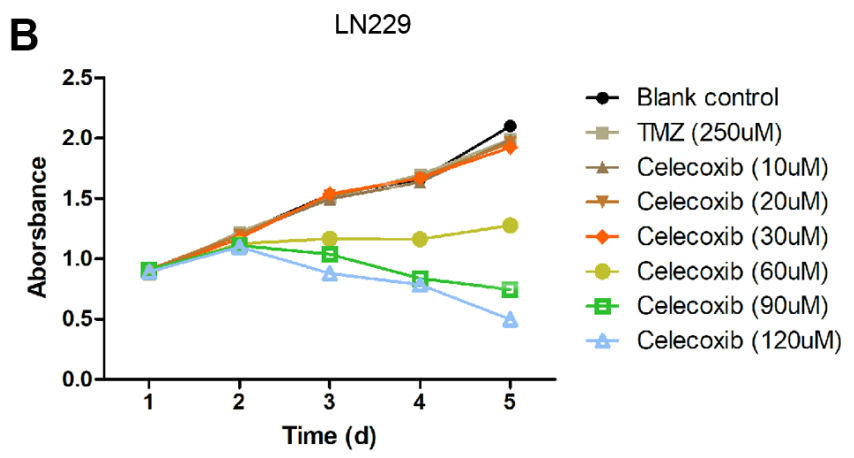

Figure 1. Cytostatic effects of celecoxib on GBM LN18 and LN229 cells assay by MTS. (A) LN18 cells $\left(5 \times 10^{3}\right)$ were seeded into $96-$ well plates, and the absorbance of the cells was detected at day 1 to day 5 in culture medium under various conditions, as indicated. (B) LN229 cells $\left(5 \times 10^{3}\right)$ were seeded into 96 -well plates, and the absorbance of the cells was detected at day 1 to day 5 in culture medium under various conditions, as indicated. Data shows mean Absorbance 490nm and $\pm S E M$, four independent wells per condition. 


\section{Celecoxib can enhance the anti-clone formation effect of TMZ on GBM}

The LN229 and LN18 cell lines have been treated with TMZ, celecoxib and combination with 10-14d, then tested by the crystal violet staining (CVS) assay. The results showed LN229, and LN18 cell lines proliferation had been inhabited (Figure 3A, 3B). Especially the combined therapy was more sensitive
(Figure 3C, 3D) than single one. The LN229 was more sensitive to the combined therapy (TMZ $250 \mathrm{uM}+$ celecoxib 30uM) than LN18 (Figure 3B) clearly from the quantitative analysis (Figure 3C and Supplementary Table 3). This further confirmed the MTS results (Figure 2A, 2B), TMZ-resistant GBM cells were killed by $\mathrm{TMZ}$ under the subsidy of celecoxib. And these were basically consistent with previous research [17].
A

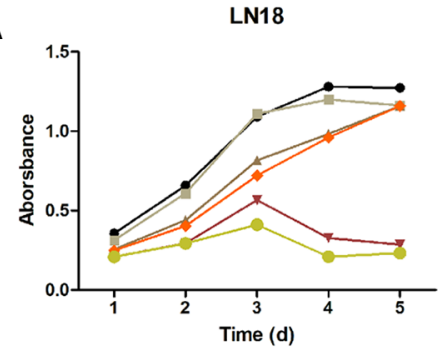

B

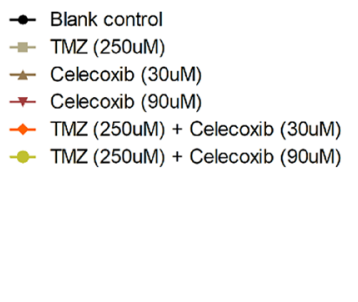

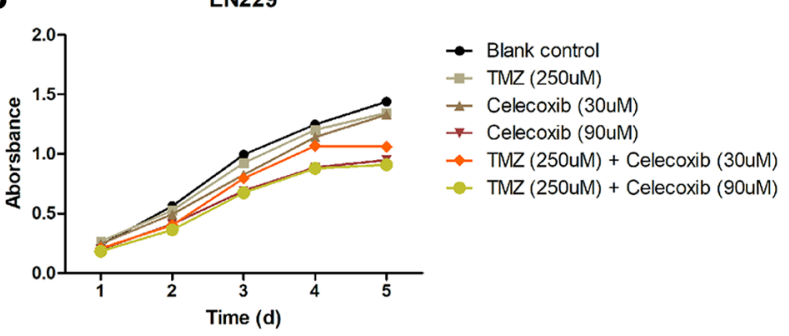

Figure 2. Cytostatic effects of TMZ and/or celecoxib on LN18 and LN229 GBM cells assay by MTS. (A) LN18 cells $\left(5 \times 10^{3}\right)$ were seeded into 96-well plates, and the absorbance of the cells was detected at day1 to day 5 in culture medium under various conditions, as indicated. (B) LN229 cells $\left(5 \times 10^{3}\right)$ were seeded into 96 -well plates, and the absorbance of the cells was detected at day 1 to day 5 in culture medium under various conditions, as indicated. Data shows mean Absorbance $490 \mathrm{~nm}$ and $\pm \mathrm{SEM}$, four independent wells per condition.

A

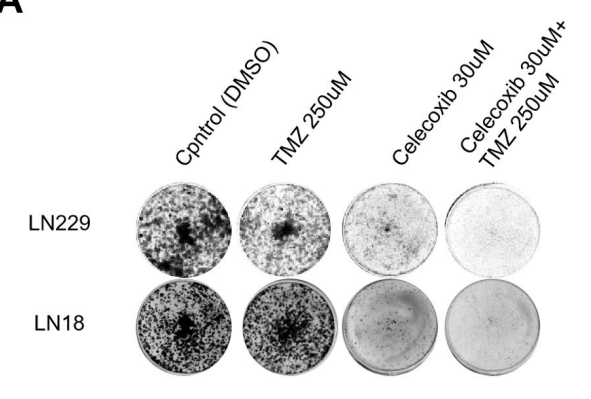

C

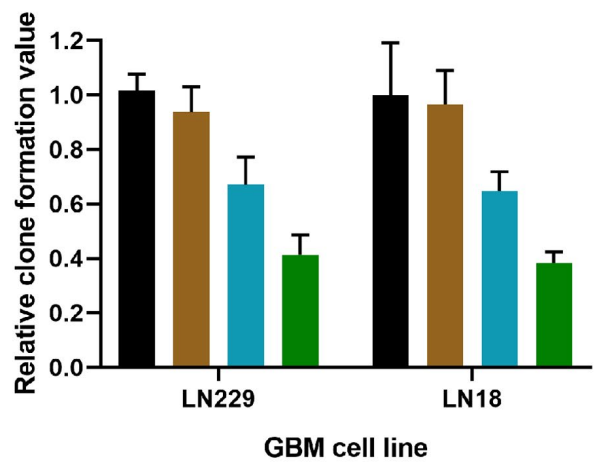

B

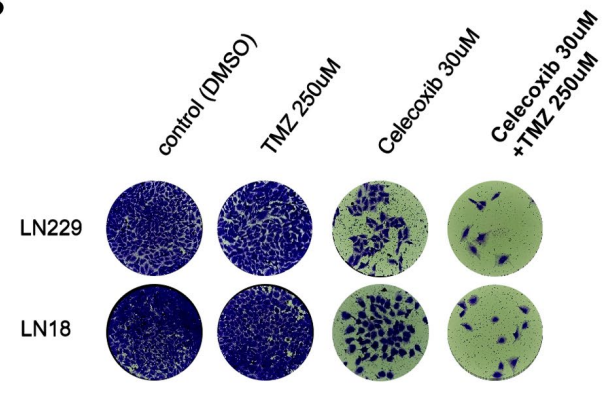

Figure 3. TMZ and/or celecoxib inhibited colony formation on LN18 and LN229 GBM cells via assay by crystal violet staining. (A) LN18 and LN229 GBM cells $\left(2.5 \times 10^{3}\right)$ were seeded into 12-well plates, following TMZ and/or celecoxib treatment for 12 days prior to staining. Then the plates were imaged by Bio-Rad equipment. $(n=5)$. (B) After staining of LN18 and LN229 GBM cells, the plates were imaged by EVOS Cell Imaging Systems. (C) The staining plates were calculated by Image Lab software, and the chart was shown the (A) result. Data shows mean Value and \pm SEM $(n=5)$. 


\section{Celecoxib can enhance the pro-apoptotic effect of TMZ on GBM}

Apoptosis is an important mechanism of anti-tumor drugs [18]. To address the cellular mechanism of effective for the combination therapy to the GBM. LN229 and LN18 have been treated with TMZ in the presence or absence of celecoxib for $72 \mathrm{~h}$ and have been stained the cells with PSVue 643 and Propidium Iodide for apoptosis analysis by FACS. The results showed that combination treatment with celecoxib resulted in a significant enhancement of apoptosis in these cell cultures (Figure 4A, 4B and Supplementary Table 4).

To account for cell apoptosis, LN229 and LN18 have been treated with TMZ in the presence or absence of celecoxib for $48 \mathrm{~h}$ and have been stained the cells with Hoechst 33342 and Propidium Iodide, then analysis with fluorescence microscope. The results showed that the combined treatment significantly enhances cell apoptosis (Figure 4D, 4E). Together, these results showed that GBM cell treated with combined therapy (TMZ 250uM+celecoxib 30uM) has been induced apoptosis significantly.

\section{The sensitization effect of celecoxib on TMZ might be via OXPHOS and mitobiogenesis}

To find the underlying molecular mechanism of how celecoxib enhances the TMZ inhibited the GBM, we treated the LN229 and LN18 with TMZ in the presence or absence of celecoxib for $72 \mathrm{~h}$ and collected the proteins, then did the western blot $(\mathrm{Wb})$ assay of oxidative phosphorylation (OXPHOS) and mitobiogenesis proteins. First, these two cell lines showed the down regulated the COX-2 protein during being treated with the celecoxib regardless of the existence of TMZ (Figure 5A). Second, the OXPHOS protein changes were observed, which were represented as complexes I, II, V down regulated during being treated with the combination therapy (Figure 5B). Finally, Mitobiogenesis protein changed in GBM cell lines, which were represented as NRF2 down regulated and LC3B up regulated during treated with the combination therapy (Figure $5 \mathrm{C}$ ).

Oliva et al. [7]. reported that TMZ-mediated alterations in mitochondrial DNA (mtDNA) and respiratory function contribute to TMZ-dependent acquired chemoresistance. In our study, the results showed that control group respiratory complexes I, II, V were high express, in contrast, they were down regulated when the LN229 and LN18 were treated with 30uM celecoxib in the presence or absence of TMZ. The COX-2 was also a part of the complexes IV [19], and it was down regulated when the LN229 and LN18 treated with celecoxib with or without the TMZ, show that the part of complexes IV was also destroyed. Collectively, similar to previous research points [7], our results suggested that celecoxib could make the resistant GBM cells regain sensitivity to TMZ by impact the electron transport chain (ETC). Previous study showed that TMZ induced profound changes in the activities of the mitochondrial ETC and cellular bioenergetic function [7]. OXPHOS has a central role in cellular energy, the OXPHOS electron transport chain (ETC) comprises four complexes (I to IV) that transfer electrons from donors generated by the TCA cycle and fatty acid oxidation to oxygen, Complex V (F0F1 ATP synthase) uses the stored energy in the proton gradient to generate ATP. Shi et al. [20] also reported that inhibits the activity of F0F1ATP synthase would specifically inhibit the growth of high-throughput GBM sphere cells. Our results showed that celecoxib inhibited the complexes $\mathrm{V}$ and increased sensitivity of TMZ to resistant GBM cells consistent with recently study [20].

Mitochondrial transcription factor A (TFAM) is a protein that maintains mtDNA integrity [21]. In GBM, the TFAM RNA and protein levels are upregulated, compared to non-neoplastic brain tissue [22], and the protein levels of TFAM are positively correlated with the malignancy of GBM [23]. In our study, the TFAM has been down regulated in LN229 and LN18 by celecoxib and combination therapy (Figure 5B). This suggested that the combination and celecoxib influenced the TFAM and down regulated the TFAM and consistent with the previous results, the complexes I, II, V (Figure 5B).

In our study, the LN229 and LN18 treated with celecoxib in the presence of TMZ shown the significantly upregulated of LC3B (Figure 5C), consistent with previous research that celecoxib induced marked autophagy [15], particularly in hypoxic cells [14]. And previous research has proven that highly aggressive brain tumors characterized by profound hypoxia, especially in the GBM [24, 25]. In our study, the p62 is upregulate while the LC3B upregulated at the protein levels in the LN229 cells when treated with celecoxib and TMZ (Figure 5C). This is consistent with previous study, that is both p62 and LC3 proteins are highly expressed in mouse tumor implantation model when the tumor is reduced [26]. We also observed the NRF2 was down regulated on LN229 and LN18 cells which treated with celecoxib in the presence or absence of TMZ, but the combination was more significant which was the respond of the oxidative stress (Figure 5B).

\section{DISCUSSION}

GBM is a serious malignant tumor of the central nervous system, and because of its chemo-resistance has brought 
A

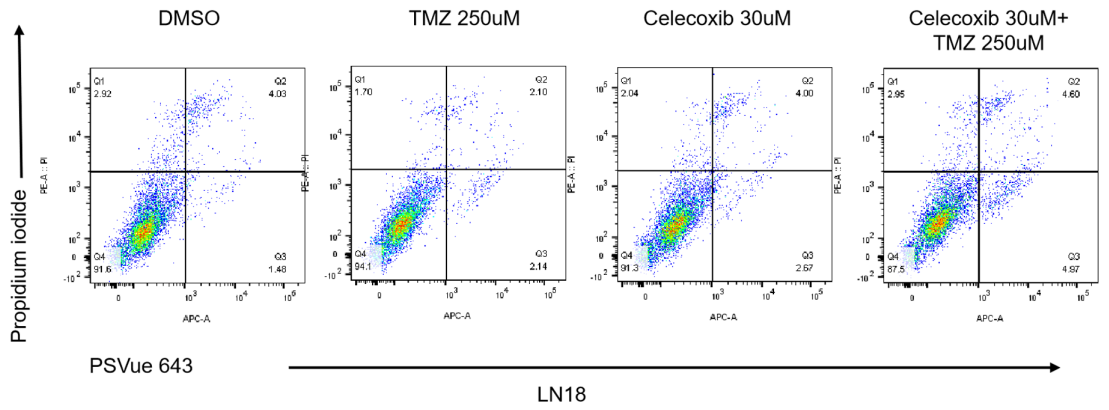

B

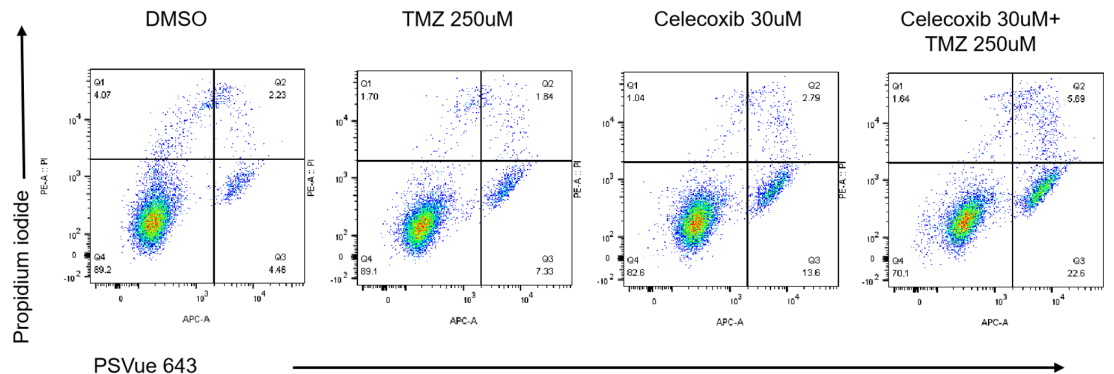

C
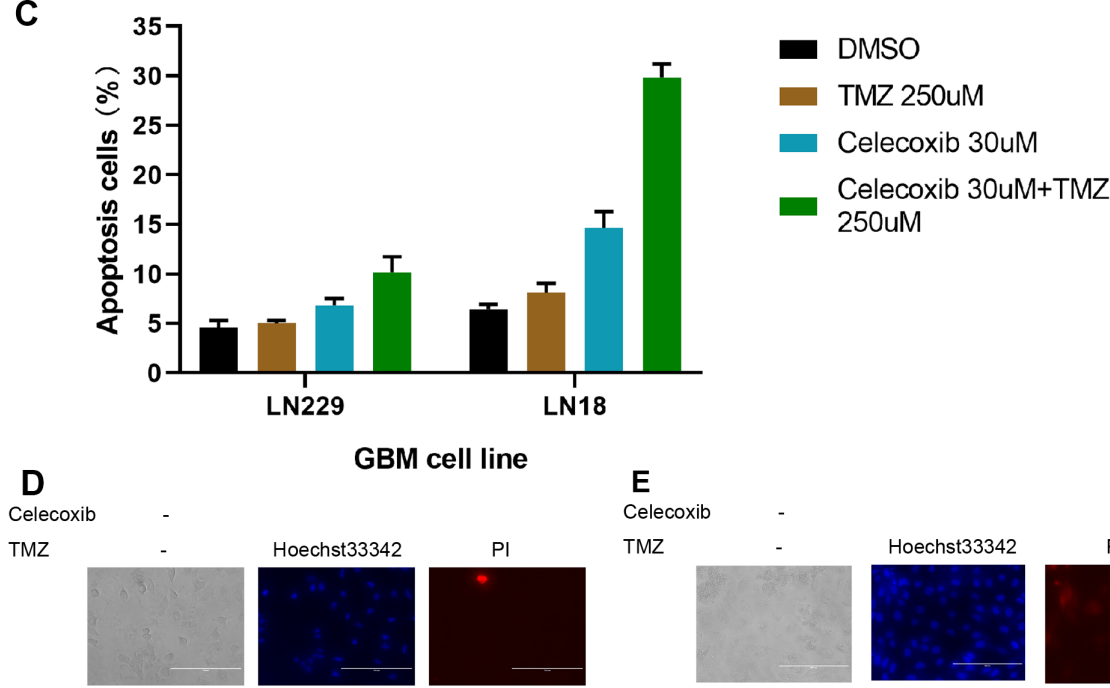

GBM cell line

Celecoxi
TMZ

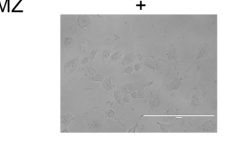

Celecoxib

TMZ

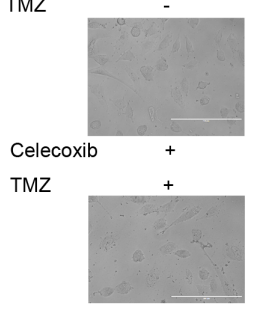

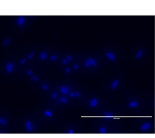
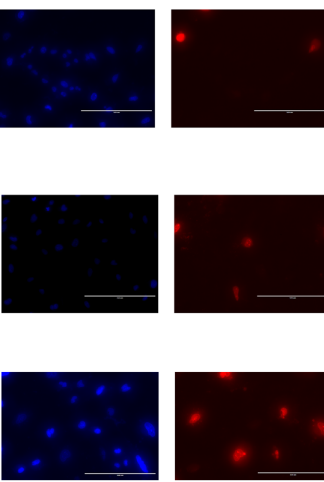
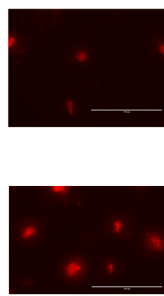
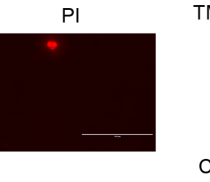

Celecoxi

TMZ

E

TMZ

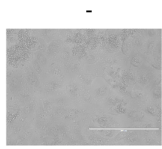

Hoechst33342
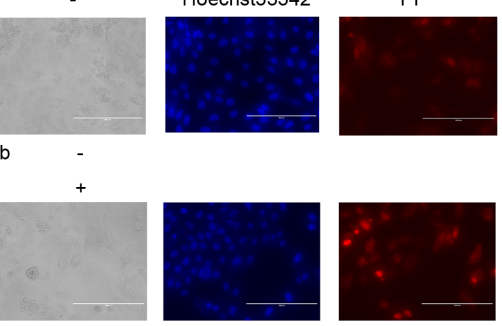

Celecoxib +

TMZ
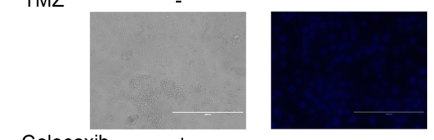

Celecoxib +

TMZ
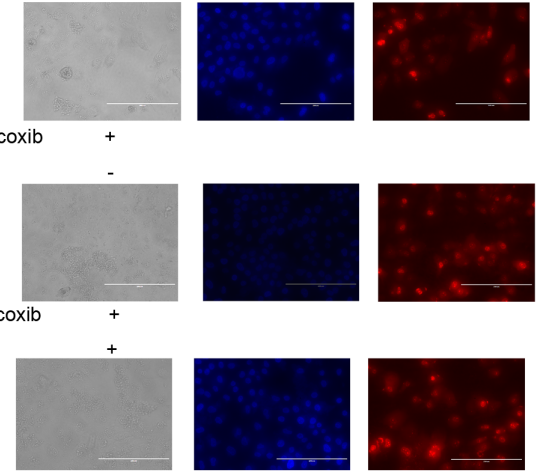

Figure 4. TMZ and/or celecoxib induces cell apoptosis in LN18 and LN229 GBM cells (A) the LN229 cells (5×103) were seeded into 12 -well plates, (three independent wells per condition) following TMZ and/or celecoxib treatment for 72 hours prior to assay. Then the cells were 
collected and washed twice with cold PBS and incubated with PI and PSVue 643 at room temperature for 30mins before test by flow cytometer. (B) The LN18 cells were practice as same condition. (C) The statistical results of the flow cytometry analysis of cell apoptosis. Data shows mean Value and \pm SEM ( $n=5)$. (D) The LN229 cells $\left(5 \times 10^{3}\right)$ were seeded into 12-well plates, (three independent wells per condition) following TMZ and/or celecoxib treatment for 48 hours prior to assay. Then the cells were collected and washed twice with cold PBS and incubated with PI and Hoechst 33342 at dark room for 5mins then test with Fluorescence microscopy. (E) The LN18 cells were practice as same condition (Standard line: 200um).

great challenges to treatment. TMZ can effectively against human cancers such as melanomas and astrocytoma [27-30]. It was approved by the U.S. Food and Drug Administration (FDA) for use in the treatment of refractory anaplastic astrocytoma in adults in 1999 and newly diagnosed adult GBM patients in 2005 [2]. Regardless of advanced diagnostic modalities and ideal multidisciplinary treatment that includes maximal surgical resection, followed by radiotherapy plus concomitant and maintenance TMZ chemotherapy, almost all patients experience tumor progression with nearly universal mortality. The median survival from initial diagnosis is less than 15 months, with a 2-year survival rate of $26-33 \%[2,31]$, and patients with initial tumor control will inevitably relapse or progress during or after TMZ therapy. Thus, both constitutive and acquired glioma cell resistances to alkylating chemotherapy are major clinical challenges [12].

There were many underlying mechanisms of TMZ resistance. The most characterized culprit of TMZ resistance is the enzyme methylguanine DNAmethyltransferase (MGMT), and MGMT levels have thus been closely associated with clinical outcomes in GBM patients [11,32]. However, this mechanism is not indisputable. Some studies have confirmed the MGMT is the main factor of TMZ-resistance, other study has objected to that cause of the tumors with the p53 mutated is resistance to TMZ [33, 34]. There is study also show that the cancer stem cells (CSC) is a potential cause of TMZ resistance [35]. Because of so many types of GBM cell line, there is no consensus on which mechanisms affects the resistance of TMZ. All data indicate that TMZ resistance results from a complex cellular response by the GBM cells [36-38]. Although TMZ has been shown to be effective in the treatment of GBM, the TMZ resistance in GBM was common, especially for relapsed acquired chemoresistance GBM, which suggests that developing a new strategy that can increase TMZ sensitivity to GBM is very necessary.

A Phase II clinical trial by the Sidney Kimmel Comprehensive Cancer Center and NCI studied the effectiveness of celecoxib in treating patients who were under treatment with antiepileptic drugs and radiation therapy for newly diagnosed GBM (https://clinicaltrials. gov/show/NCT00068770). Unfortunately, the trial was terminated because an ethical concern. But this given a revelation that the combination $\mathrm{TMZ}$ with celecoxib would be a feasible strategy to the GBM. Previous studies have proved that TMZ combined with COX-2 inhibitors can be effective treatment for GBM in vivo and in vitro but did not explain the molecular mechanism [8, 39]. In our study, it confirms the previous conclusion in vitro (Figures 2,3 ) and this phenomenon is related to mitochondrial metabolism (Figure 5B).

Shono, T. et al. [40] have reported that high COX-2 expression in tumor cells is associated with clinically more aggressive gliomas and is a strong predictor of poor survival. Most brain tumors, including astrocytoma, glioblastoma, meningioma, medulloblastoma, highly expressed $\mathrm{COX}-2$, and most human malignant glioma cell lines show constitutively elevated levels of COX-2, and an increasing body of evidence from preclinical and clinical studies suggests that elevated COX-2 activity in turn contributes to GBM genesis and progression [41-44]. Our data confirmed that the combination treatment significantly inhibited cell growth than the treatment with TMZ alone which suggests that celecoxib can improve the efficacy of TMZ (Figures 1,2). A recent study also showed that COX-2 played complex roles in glioma invasion, angiogenesis, immunosuppression, etc. Overexpressed COX-2 contributes to the glioblastoma progression [44]. There were some contradictions about COX-2 inhibitors to GBM invasion, which was probably due to the different type of COX-2 inhibitors. And celecoxib has been reported more potent than those of other selective COX-2 inhibitors or traditional NSAIDs, and which were mediated via the transcriptional inhibition of two essential components of the cell cycle machinery, cyclin A and cyclin B [45]. Our study did not focus on the GBM invasion, follow-up study could be further carried out.

Many studies have explained that the characters of the Warburg effect, tumor hypoxia, genetic mutations, and mitochondrial abnormalities within proliferating cancer cells. Oxidative phosphorylation or electron transportlinked phosphorylation or terminal oxidation) is the metabolic pathway in which cells use enzymes to oxidize nutrients. And this takes place inside mitochondria in eukaryotes. The electron transport chain is a set of enzymes which consisting of complexes I through IV, and the ATP synthase, also called complex $\mathrm{V}$, is the final enzyme in the oxidative phosphorylation pathway. The previous study has shown that the TMZ 
resistance in Gliomas may due to a mitochondrial adaptive response to TMZ genotoxic stress [7]. Hence, our study focused on the changes of the mitochondrial metabolic enzymes in the LN229 and LN18 cell lines treated with the combination therapy.

A recent study showed that the GBM cancer stem cells (CSC) were primarily responsible for metastatic dissemination, resistance to therapy, and relapse of GBM, LN229 was CSC-enriched GBM cell lines, and easier to resistance to therapy and relapse of GBM [46]. In our data, the LN18 was more effective to the combination therapy than LN229 (Figures 1, 2, and Supplementary Tables 1, 2), possible due to that LN229 was CSCenriched and more resistance to drug [44]. Collectively, the data indicate that when the LN229 and LN18 treated with $30 \mathrm{uM}$ celecoxib, the complex I, II, V were downregulated, in the presence or absence of $\mathrm{TMZ}$ (Figure 5B). This suggest that the $30 \mathrm{uM}$ celecoxib could acts the ETC and induce the apoptosis (Figure 5C).

Apoptosis as a mechanism of mediated cell death has been widely studied [47], and which is thought to be an anti-cancer molecular mechanism. One of the main apoptotic pathways is intrinsic mitochondrial pathway [48], our study show first found that the celecoxib and combination therapy acts on ETC of mitochondrial and induces the GBM apoptosis by modulating the intrinsic pathway of apoptosis. This result is consistent with previous study that celecoxib could induce apoptosis through the mitochondrial pathway [49]. Jendrossek, V. et al. [50] also concludes that celecoxib induces apoptosis independently from its COX-2 inhibitory action via a mitochondrial apoptosis pathway. The crosstalk between autophagy and apoptosis in cancer is complex, some study point out that the autophagy could suppress apoptosis [51], but others suggest the autophagy could promote apoptosis in certain physiological process of cancer $[52,53]$. In our study, the results show that the autophagy increased when the GBM cell lines treated with the combination therapy, and consistent with the latter studies. The autophagy could promote apoptosis in GBM, and this process is due to the celecoxib especially combination therapy.

Our study revealed that the celecoxib significantly enhanced the chemo-sensitization of LN18, this could be demonstrated by the results of cell proliferation,

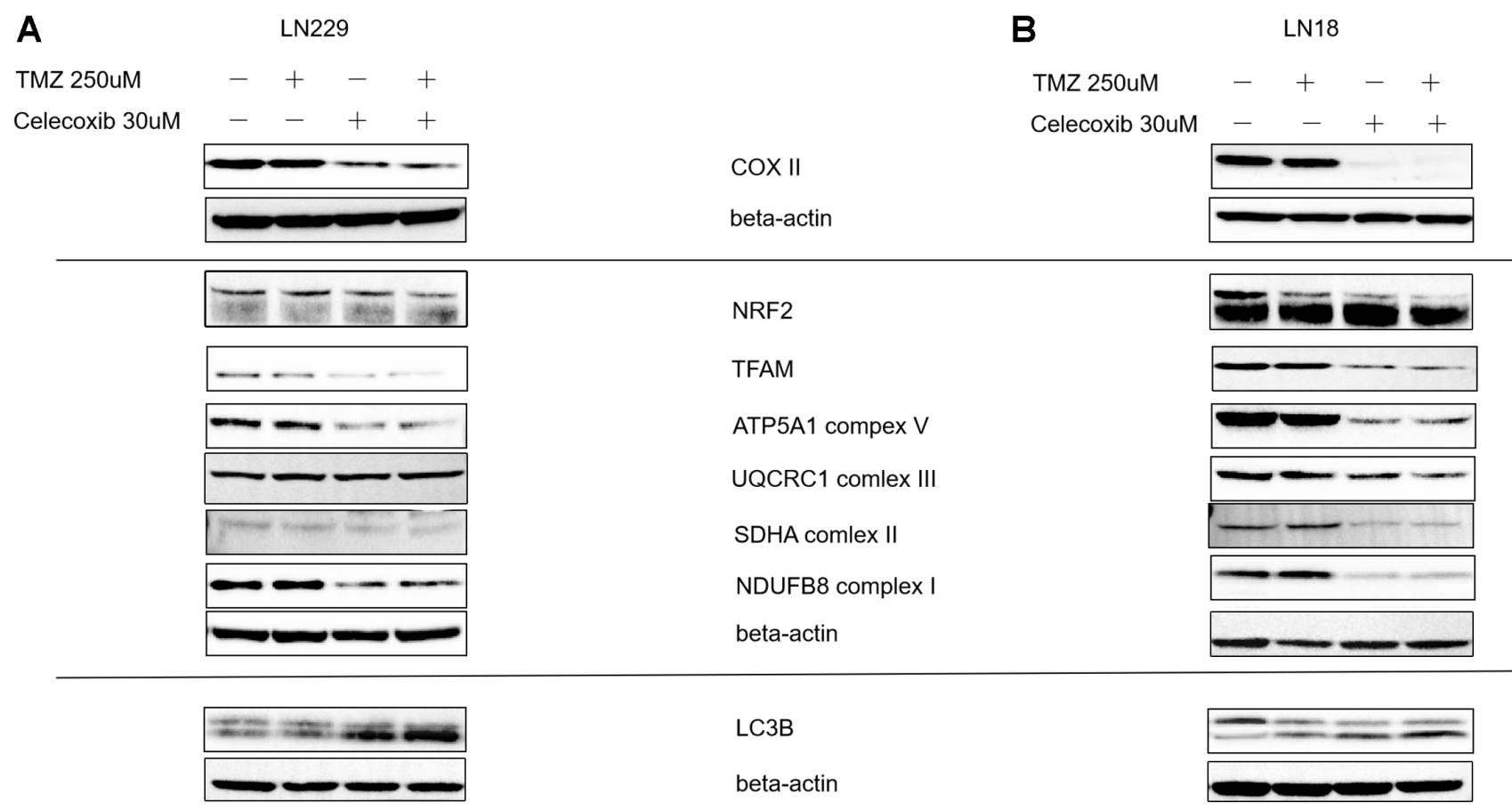

Figure 5. Regulator of MitoBiogenesis proteins and OXPHOS Subunits were modulated by celecoxib in GBM LN229 and LN18 cells. (A, B) LN229 and LN18 cells $\left(2 \times 10^{5}\right)$ were seeded into 6-well plates, (three independent wells per condition) following TMZ and/or celecoxib treatment for 48 hours prior to assay. Then the lysates harvested were analyzed by Western blotting for various proteins using Beta-Actin as a loading control as indicated. The COX-II was down-regulated by Celecoxib. The OXPHOS Subunits such as complex I, II, V were down-regulated by celecoxib compare the Beta-actin as standard. And the TFAM which was the regulator MitoBiogenesis protein also was down regulated in LN229. The MitoBiogenesis proteins NRF2 was downregulated by celecoxib, combination therapy was more significant. The LC3 protein tends to increase when the LN229 and LN18 were treated with celecoxib and combination. 
apoptosis, and clone formation. The main reason may be due to the high expression of COX-2 on LN18. When we applied the celecoxib, which is the specific inhibitor of COX-2, the levels of COX-2 were down regulated significantly on LN18. As well as the complex I, II, V, TFAM, NRF2 down regulated significantly (Figure 5). Even the complex III is also downregulated in LN18, but not significantly in LN229 (Figure 5). This finding suggests that the expression of COX-2 might be a new biomarker for chemo sensitization in GBM patients. On the other hand, our study identified the molecular mechanisms of the celecoxib reverses chemo-resistance of GBM to TMZ by inhibiting the OXPHOS, promoting apoptosis and autophagy.

We conclude from these data that the combination therapy (TMZ 250uM+celecoxib $30 \mathrm{uM}$ ) inhibits cell proliferation, increases apoptosis, and increases the autophagy on LN229 and LN18, which were TMZ resistant GBM cell lines. Celecoxib would reverse chemo-resistance of GBM to TMZ in vitro, consistent with previous study [44]. And this study first shows that the potential molecular mechanisms related to mitochondrial metabolism and respiratory chain inhibition. New treatments for GBM are urgently needed and combining celecoxib with temozolomide-based therapy may improve the outcome of these patients.

\section{MATERIALS AND METHODS}

\section{Chemicals and reagent}

TMZ was obtained from Sigma-Aldrich (St. Louis, USA, T2577) and was dissolved in dimethyl sulfoxide (DMSO) Sigma-Aldrich (St. Louis, USA, D2650) to obtain a final concentration of $100 \mathrm{mM}$. Celecoxib was obtained from Sigma-Aldrich (St. Louis, USA, PZ0008) which was also dissolved in DMSO to obtain a final concentration of $100 \mathrm{mM}$. DMSO was kept below 0.35 $\%$ in all cell culture experiments. MTS was obtained from Promega (Fitchburg, WI, USA, G3582). Crystal violet was obtained from Sigma-Aldrich (St. Louis, USA, AC405830250). Hoechst 33342/Propidium Iodide was obtained from Thermo Fisher Scientific (ShangHai, China, V13244). PSVue 643 was obtained from Molecular Targeting Technologies (West Chester PA, USA, P-1006).

\section{Cell lines and culture conditions}

Human GBM cells, LN18 and LN229, were purchased from American Type Culture Collection (ATCC) and cultured following their culture procedures. The cells were cultured with Dulbecco's minimum essential medium (DMEM) containing 10\% fetal bovine serum (FBS) and cultured at $37^{\circ} \mathrm{C}$ and in $5 \% \mathrm{CO} 2$.

\section{Cell cytotoxicity / proliferation assay with MTS}

Cell cytotoxicity / Proliferation was performed as following. Briefly, Plate cells at appropriate density (5000 cells/well) in 100uL media (3 wells per condition). And make sure to have three wells with only media at the bottom, add $50 \mathrm{uL}$ diH20 to outside wells to control for edge effects. The cells adhere to plate after incubating for 24hrs, then add 20uL CellTiter 96® AQueous One Solution Reagent to Day 0 wells (want 5 parts media: 1 part MTS reagent; ex. 100ml media:20ul MTS reagent), then absorbance was measured at $490 \mathrm{~nm}$ after $1 \mathrm{hr}$.

\section{Crystal violet staining assay}

Crystal violet staining was performed as following. Briefly, Plate cells at appropriate density (2000 cells/well) with media contains TMZ, cultured for 2 weeks. Then take off media, to making sure not to touch top to bottom of well. Wash wells with $1 \mathrm{X}$ cold PBS and add $0.5 \mathrm{ml} 0.25 \%$ crystal violet staining solution to each well, then incubate at room temperature for 30 minutes. Take off crystal violet and dispense into waste bottle. Keep plate submerged and keep water running until water in tub is no longer purple. Place plates upside down and leave to dry overnight.

\section{Fluorescence-activated cell sorting (FACS) assay}

The cell-apoptosis was determined by flow cytometry. The cells were treated with TMZ, celecoxib, combination for $72 \mathrm{~h}$, then harvested. They were then pelleted, washed with PBS and resuspended in propidium iodide (PI) solution $(50 \mu \mathrm{g} / \mathrm{mL}$ PI, $0.5 \mathrm{mg} / \mathrm{mL}$ RNase staining buffer) and PSVue 643 for $15 \mathrm{~min}$ in the dark. Data were collected and analyzed using the Cellfit program with a FACS can flow cytometer (FACS Canto II Cytometer: BD Biosciences, San Jose, CA).

\section{Western blot analysis}

Cells were washed twice with PBS and lysed with a lysis buffer (Trizma base $50 \mathrm{mM}$, sucrose $0.25 \mathrm{mM}$, EDTA $5 \mathrm{mM}$ and triton $\mathrm{X}-100 \quad 0.5 \%, \mathrm{pH}$ 7.4). Protein concentration was determined using Bradford Reagent (Bio-Rad) after sonication. Thus, $25 \mu \mathrm{g}$ of protein was electrophoretically separated by $12 \%$ SDS-PAGE and transferred to nitrocellulose membranes. These membranes were blocked for $60 \mathrm{~min}$ at room temperature in $5 \%(\mathrm{w} / \mathrm{v})$ milk powder in TBS containing $0.1 \%$ Tween 20 , co-incubated overnight at $4^{\circ} \mathrm{C}$ with the primary antibodies (TFAM 1:1000, LC3B 1:1000, Cell Signaling Technology; ATP5A1 1:500, NDUFB8 1:500, SDHA 1:500, UQCRC1 1:500, NRF2 1:600, COX2 1:600, Proteintech; $\beta$-actin 1:10000, Cell Signaling Technology), washed three times with $0.1 \%$ Tween 20 in TBS, and 
incubated for $1 \mathrm{~h}$ with a horseradish peroxidaseconjugated (HRP) goat anti-Rabbit secondary antibody 1:5000 (Cell Signaling Technology). Proteins were visualized using the ECL system (Amersham Biosciences, USA) in the Bio-Rad equipment. Further analysis, as well as image processing and quantification of the bands, was performed using the program Image lab. Expression was normalized relative to the $\beta$-actin level.

\section{Fluorescence microscopy assay}

Hoechst 33342 and PI staining were performed as the protocol. Briefly, the GBM cells of control, TMZ, celecoxib, and combination groups were prepared in the 12 well-plates after treated with inhibitors $36 \mathrm{~h}$, and then the Hoechst33342 and PI solution by diluting the Hoechst stock solution 1:2000 in PBS and the same dilution of the PI in the same PBS. Remove the media, add sufficient staining solution 300ul to cover the cells, and incubate for 5-10mins in the dark room. Finally, the images were collected by using EVOS Cell Imaging Systems f1 (Thermo Fisher Scientific, USA).

\section{Statistical analysis}

Experimental data is presented as the mean \pm standard deviation of three experimental repeats. GraphPad Prism 8.0 (GraphPad Software Corp., USA) was used to perform a two-way ANOVA analysis of variance with the least significant difference post hoc test. $\mathrm{P} \leq 0.05$ was considered to indicate a statistically significant difference.

\section{Abbreviations}

TMZ: Temozolomide; GBM: Glioblastoma; COX-2: Cyclooxygenase-2; CVS: violet staining; OXPHOS: oxidative phosphorylation; mtDNA: mitochondrial DNA; ETC: electron transport chain; FDA: Drug Administration; TFAM: Mitochondrial transcription factor A; DMSO: dimethyl sulfoxide; CSC: cancer stem cells; ATCC: American Type Culture Collection.

\section{AUTHOR CONTRIBUTIONS}

Yin Delong and Jin Guoqing conducted experiments, He Hong done the data sorting and analysis, Zhou Wei done the assist in the completion of experimental data analysis, Fan Zhenbo coordinate to complete the experiment, Gong Chen worked on statistical analysis and revised the paper, Zhao Jing and Xiong Huihua designed experiments and revise manuscripts.

\section{ACKNOWLEDGMENTS}

The authors acknowledge Gao Zhang (Duke University) for technical support.

\section{CONFLICTS OF INTEREST}

The authors have no conflicts of interest to declare.

\section{FUNDING}

This work was supported by The Third Affiliated Hospital of Guangzhou Medical University.

\section{REFERENCES}

1. Brat DJ, Scheithauer BW, Fuller GN, Tihan T. Newly codified glial neoplasms of the 2007 WHO Classification of Tumours of the Central Nervous System: angiocentric glioma, pilomyxoid astrocytoma and pituicytoma. Brain Pathol. 2007; 17:319-24. https://doi.org/10.1111/i.1750-3639.2007.00082.x PMID: $\underline{17598825}$

2. Stupp R, Mason WP, van den Bent MJ, Weller M, Fisher B, Taphoorn MJ, Belanger K, Brandes AA, Marosi C, Bogdahn U, Curschmann J, Janzer RC, Ludwin SK, et al, and European Organisation for Research and Treatment of Cancer Brain Tumor and Radiotherapy Groups, and National Cancer Institute of Canada Clinical Trials Group. Radiotherapy plus concomitant and adjuvant temozolomide for glioblastoma. N Engl J Med. 2005; 352:987-96. https://doi.org/10.1056/NEJMoa043330 PMID:15758009

3. Lan F, Pan $Q, Y u ~ H$, Yue X. Sulforaphane enhances temozolomide-induced apoptosis because of downregulation of miR-21 via $W n t / \beta$-catenin signaling in glioblastoma. J Neurochem. 2015; 134:811-18. https://doi.org/10.1111/inc.13174 PMID:25991372

4. Lee JH, Jung TY, Jung $\mathrm{S}$, Kim IY, Jang WY, Moon KS, Jeong EH. Performance status during and after radiotherapy plus concomitant and adjuvant temozolomide in elderly patients with glioblastoma multiforme. J Clin Neurosci. 2013; 20:503-08. https://doi.org/10.1016/i.jocn.2012.03.044 PMID:23313530

5. Stupp R, Hegi ME, Mason WP, van den Bent MJ, Taphoorn MJ, Janzer RC, Ludwin SK, Allgeier A, Fisher B, Belanger K, Hau P, Brandes AA, Gijtenbeek J, et al, and European Organisation for Research and Treatment of Cancer Brain Tumour and Radiation Oncology Groups, and National Cancer Institute of Canada Clinical Trials Group. Effects of radiotherapy with concomitant and adjuvant temozolomide versus radiotherapy alone on survival in glioblastoma in a randomised phase III study: 5-year analysis of the EORTC-NCIC trial. Lancet Oncol. 2009; 10:459-66. https://doi.org/10.1016/S1470-2045(09)70025-7 PMID:19269895 
6. Parker NR, Correia N, Crossley B, Buckland ME, Howell VM, Wheeler HR. Correlation of MicroRNA 132 Upregulation with an Unfavorable Clinical Outcome in Patients with Primary Glioblastoma Multiforme Treated with Radiotherapy Plus Concomitant and Adjuvant Temozolomide Chemotherapy. Transl Oncol. 2013; 6:742-48.

https://doi.org/10.1593/tlo.13553 PMID:24466377

7. Oliva CR, Nozell SE, Diers A, McClugage SG 3rd, Sarkaria JN, Markert JM, Darley-Usmar VM, Bailey SM, Gillespie GY, Landar A, Griguer CE. Acquisition of temozolomide chemoresistance in gliomas leads to remodeling of mitochondrial electron transport chain. J Biol Chem. 2010; 285:39759-67.

https://doi.org/10.1074/jbc.M110.147504

PMID:20870728

8. Joki T, Heese O, Nikas DC, Bello L, Zhang J, Kraeft SK, Seyfried NT, Abe T, Chen LB, Carroll RS, Black PM. Expression of cyclooxygenase 2 (COX-2) in human glioma and in vitro inhibition by a specific COX-2 inhibitor, NS-398. Cancer Res. 2000; 60:4926-31. https://cancerres.aacrjournals.org/content/60/17/4 $\underline{926}$

PMID:10987308

9. Buccoliero AM, Caldarella A, Gheri CF, Taddei A, Paglierani M, Pepi M, Mennonna P, Taddei GL. Inducible cyclooxygenase (COX-2) in glioblastoma-clinical and immunohistochemical (COX-2-VEGF) correlations. Clin Neuropathol. 2006; 25:59-66.

PMID:16550738

10. Grossman SA, Olson J, Batchelor T, Peereboom D, Lesser G, Desideri S, Ye X, Hammour T, Supko JG, and New Approaches to Brain Tumor Therapy CNS Consortium. Effect of phenytoin on celecoxib pharmacokinetics in patients with glioblastoma. Neuro Oncol. 2008; 10:190-98.

https://doi.org/10.1215/15228517-2007-055

PMID:18287342

11. St-Coeur PD, Poitras JJ, Cuperlovic-Culf M, Touaibia M, Morin P Jr. Investigating a signature of temozolomide resistance in GBM cell lines using metabolomics. J Neurooncol. 2015; 125:91-102.

https://doi.org/10.1007/s11060-015-1899-6

PMID:26311249

12. Happold C, Roth P, Wick W, Schmidt N, Florea AM, Silginer $M$, Reifenberger $G$, Weller $M$. Distinct molecular mechanisms of acquired resistance to temozolomide in glioblastoma cells. J Neurochem. 2012; 122:444-55.

https://doi.org/10.1111/i.1471-4159.2012.07781.x PMID:22564186

13. Lee SY. Temozolomide resistance in glioblastoma multiforme. Genes Dis. 2016; 3:198-210. https://doi.org/10.1016/i.gendis.2016.04.007 PMID:30258889

14. Suzuki K, Gerelchuluun A, Hong Z, Sun L, Zenkoh J, Moritake T, Tsuboi K. Celecoxib enhances radiosensitivity of hypoxic glioblastoma cells through endoplasmic reticulum stress. Neuro Oncol. 2013; 15:1186-99.

https://doi.org/10.1093/neuonc/not062 PMID:23658321

15. Kang KB, Zhu C, Yong SK, Gao Q, Wong MC. Enhanced sensitivity of celecoxib in human glioblastoma cells: Induction of DNA damage leading to p53-dependent G1 cell cycle arrest and autophagy. Mol Cancer. 2009; 8:66. https://doi.org/10.1186/1476-4598-8-66 PMID:19706164

16. Yamaguchi I, Nakajima K, Shono K, Mizobuchi Y, Fujihara T, Shikata E, Yamaguchi T, Kitazato K, Sampetrean O, Saya H, Takagi Y. Downregulation of PD-L1 via FKBP5 by celecoxib augments antitumor effects of PD-1 blockade in a malignant glioma model. Neurooncol Adv. 2019; 2:vdz058.

https://doi.org/10.1093/noajnl/vdz058

PMID:32642723

17. Uram $Ł$, Markowicz J, Misiorek M, Filipowicz-Rachwał A, Wołowiec S, Wałajtys-Rode E. Celecoxib substituted biotinylated poly(amidoamine) G3 dendrimer as potential treatment for temozolomide resistant glioma therapy and anti-nematode agent. Eur J Pharm Sci. 2020; 152:105439.

https://doi.org/10.1016/i.ejps.2020.105439

PMID: 32615261

18. Vellanki SH, Cruz RG, Richards CE, Smith YE, Hudson L, Jahns H, Hopkins AM. Antibiotic Tetrocarcin-A Downregulates JAM-A, IAPs and Induces Apoptosis in Triplenegative Breast Cancer Models. Anticancer Res. 2019; 39:1197-204.

https://doi.org/10.21873/anticanres.13230 PMID: $\underline{30842150}$

19. Castellanos E, Lanning NJ. Phosphorylation of OXPHOS Machinery Subunits: Functional Implications in Cell Biology and Disease. Yale J Biol Med. 2019; 92:523-31.

PMID:31543713

20. Shi Y, Lim SK, Liang Q, lyer SV, Wang HY, Wang Z, Xie X, Sun D, Chen YJ, Tabar V, Gutin P, Williams N, De Brabander JK, Parada LF. Gboxin is an oxidative phosphorylation inhibitor that targets glioblastoma. Nature. 2019; 567:341-46.

https://doi.org/10.1038/s41586-019-0993-x PMID:30842654

21. Franco DG, Moretti IF, Marie SK. Mitochondria Transcription Factor A: A Putative Target for the Effect 
of Melatonin on U87MG Malignant Glioma Cell Line.

Molecules. 2018; 23:1129.

https://doi.org/10.3390/molecules23051129

PMID:29747444

22. Lee H, Park J, Tran Q, Kim D, Hong Y, Cho H, Kwon SH, Brazil D, Kim SH, Park J. Mitochondrial transcription factor A (TFAM) is upregulated in glioma. Mol Med Rep. 2017; 15:3781-86.

https://doi.org/10.3892/mmr.2017.6467

PMID:28440425

23. Jiang J, Yang J, Wang Z, Wu G, Liu F. TFAM is directly regulated by miR-23b in glioma. Oncol Rep. 2013; 30:2105-10.

https://doi.org/10.3892/or.2013.2712 PMID:24002170

24. Charles NA, Holland EC, Gilbertson R, Glass R, Kettenmann $\mathrm{H}$. The brain tumor microenvironment. Glia. 2011; 59:1169-80. https://doi.org/10.1002/glia.21136 PMID:21446047

25. Kucharzewska P, Christianson HC, Welch JE, Svensson $K J$, Fredlund $E$, Ringnér $M$, Mörgelin $M$, BourseauGuilmain E, Bengzon J, Belting M. Exosomes reflect the hypoxic status of glioma cells and mediate hypoxia-dependent activation of vascular cells during tumor development. Proc Natl Acad Sci USA. 2013; 110:7312-17.

https://doi.org/10.1073/pnas.1220998110 PMID:23589885

26. Wei H, Wang C, Croce CM, Guan JL. p62/SQSTM1 synergizes with autophagy for tumor growth in vivo. Genes Dev. 2014; 28:1204-16.

https://doi.org/10.1101/gad.237354.113

PMID:24888590

27. Middleton MR, Grob JJ, Aaronson N, Fierlbeck G, Tilgen W, Seiter S, Gore M, Aamdal S, Cebon J, Coates A, Dreno B, Henz M, Schadendorf D, et al. Randomized phase III study of temozolomide versus dacarbazine in the treatment of patients with advanced metastatic malignant melanoma. J Clin Oncol. 2000; 18:158-66. https://doi.org/10.1200/JCO.2000.18.1.158 PMID:10623706

28. Quirt I, Verma S, Petrella T, Bak K, Charette M. Temozolomide for the treatment of metastatic melanoma: a systematic review. Oncologist. 2007; 12:1114-23.

https://doi.org/10.1634/theoncologist.12-9-1114 PMID:17914081

29. Xu W, Li T, Gao L, Zheng J, Shao A, Zhang J. Efficacy and safety of long-term therapy for high-grade glioma with temozolomide: A meta-analysis. Oncotarget. 2017; 8:51758-65. https://doi.org/10.18632/oncotarget.17401 PMID:28881684
30. Wang J, Yan L, Ai P, He Y, Guan H, Wei Z, He L, Mu X, Liu $Y$, Peng $X$. Observation versus radiotherapy with or without temozolomide in postoperative WHO grade II high-risk low-grade glioma: a retrospective cohort study. Neurosurg Rev. 2021; 44:1447-55.

https://doi.org/10.1007/s10143-020-01326-y

PMID:32529528

31. Gilbert MR, Wang M, Aldape KD, Stupp R, Hegi ME, Jaeckle KA, Armstrong TS, Wefel JS, Won M, Blumenthal DT, Mahajan A, Schultz CJ, Erridge S, et al. Dose-dense temozolomide for newly diagnosed glioblastoma: a randomized phase III clinical trial. J Clin Oncol. 2013; 31:4085-91.

https://doi.org/10.1200/JCO.2013.49.6968

PMID:24101040

32. Hegi ME, Liu L, Herman JG, Stupp R, Wick W, Weller M, Mehta MP, Gilbert MR. Correlation of O6methylguanine methyltransferase (MGMT) promoter methylation with clinical outcomes in glioblastoma and clinical strategies to modulate MGMT activity. J Clin Oncol. 2008; 26:4189-99.

https://doi.org/10.1200/JCO.2007.11.5964 PMID:18757334

33. Bocangel DB, Finkelstein S, Schold SC, Bhakat KK, Mitra $\mathrm{S}$, Kokkinakis DM. Multifaceted resistance of gliomas to temozolomide. Clin Cancer Res. 2002; 8:2725-34. PMID:12171906

34. Chen $X$, Zhang $M$, Gan $H$, Wang $H$, Lee JH, Fang $D$, Kitange GJ, He L, Hu Z, Parney IF, Meyer FB, Giannini C, Sarkaria JN, Zhang Z. A novel enhancer regulates MGMT expression and promotes temozolomide resistance in glioblastoma. Nat Commun. 2018; 9:2949.

https://doi.org/10.1038/s41467-018-05373-4 PMID:30054476

35. Liu G, Yuan X, Zeng Z, Tunici P, Ng H, Abdulkadir IR, Lu $L$, Irvin D, Black KL, Yu JS. Analysis of gene expression and chemoresistance of $\mathrm{CD}_{133^{+}}$cancer stem cells in glioblastoma. Mol Cancer. 2006; 5:67. https://doi.org/10.1186/1476-4598-5-67 PMID:17140455

36. Munoz JL, Rodriguez-Cruz V, Greco SJ, Ramkissoon SH, Ligon KL, Rameshwar P. Temozolomide resistance in glioblastoma cells occurs partly through epidermal growth factor receptor-mediated induction of connexin 43. Cell Death Dis. 2014; 5:e1145.

https://doi.org/10.1038/cddis.2014.111 PMID:24675463

37. Goellner EM, Grimme B, Brown AR, Lin YC, Wang XH, Sugrue KF, Mitchell L, Trivedi RN, Tang JB, Sobol RW. Overcoming temozolomide resistance in glioblastoma via dual inhibition of NAD+ biosynthesis and base excision repair. Cancer Res. 2011; 71:2308-17. 
https://doi.org/10.1158/0008-5472.CAN-10-3213 PMID:21406402

38. Munoz JL, Bliss SA, Greco SJ, Ramkissoon SH, Ligon KL, Rameshwar P. Delivery of Functional Anti-miR-9 by Mesenchymal Stem Cell-derived Exosomes to Glioblastoma Multiforme Cells Conferred Chemosensitivity. Mol Ther Nucleic Acids. 2013; 2:e126.

https://doi.org/10.1038/mtna.2013.60

PMID:24084846

39. Kang SG, Kim JS, Park K, Kim JS, Groves MD, Nam DH. Combination celecoxib and temozolomide in $\mathrm{C} 6$ rat glioma orthotopic model. Oncol Rep. 2006; 15:7-13. https://doi.org/10.3892/or.15.1.7

PMID:16328028

40. Shono T, Tofilon PJ, Bruner JM, Owolabi O, Lang FF. Cyclooxygenase-2 expression in human gliomas: prognostic significance and molecular correlations. Cancer Res. 2001; 61:4375-81.

PMID:11389063

41. Patti R, Gumired K, Reddanna P, Sutton LN, Phillips $P C$, Reddy CD. Overexpression of cyclooxygenase-2 (COX-2) in human primitive neuroectodermal tumors: effect of celecoxib and rofecoxib. Cancer Lett. 2002; 180:13-21.

https://doi.org/10.1016/s0304-3835(02)00003-4 PMID:11911965

42. Annabi B, Laflamme C, Sina A, Lachambre MP, Béliveau R. A MT1-MMP/NF-kappaB signaling axis as a checkpoint controller of COX-2 expression in CD133+ U87 glioblastoma cells. J Neuroinflammation. 2009; 6:8.

https://doi.org/10.1186/1742-2094-6-8

PMID:19272160

43. Xu K, Wang L, Shu HK. COX-2 overexpression increases malignant potential of human glioma cells through Id1. Oncotarget. 2014; 5:1241-52. https://doi.org/10.18632/oncotarget.1370 PMID:24659686

44. Qiu J, Shi Z, Jiang J. Cyclooxygenase-2 in glioblastoma multiforme. Drug Discov Today. 2017; 22:148-56.

https://doi.org/10.1016/i.drudis.2016.09.017 PMID:27693715

45. Kardosh A, Blumenthal M, Wang WJ, Chen TC, Schönthal AH. Differential effects of selective COX-2 inhibitors on cell cycle regulation and proliferation of glioblastoma cell lines. Cancer Biol Ther. 2004; 3:55-62.

https://doi.org/10.4161/cbt.3.1.571

PMID:14726653
46. Park HK, Hong JH, Oh YT, Kim SS, Yin J, Lee AJ, Chae YC, Kim JH, Park SH, Park CK, Park MJ, Park JB, Kang BH. Interplay between TRAP1 and Sirtuin-3 Modulates Mitochondrial Respiration and Oxidative Stress to Maintain Stemness of Glioma Stem Cells. Cancer Res. 2019; 79:1369-82.

https://doi.org/10.1158/0008-5472.CAN-18-2558 PMID:30683653

47. Maiuri MC, Zalckvar E, Kimchi A, Kroemer G. Self-eating and self-killing: crosstalk between autophagy and apoptosis. Nat Rev Mol Cell Biol. 2007; 8:741-52. https://doi.org/10.1038/nrm2239 PMID:17717517

48. El-Khattouti A, Selimovic D, Haikel Y, Hassan M. Crosstalk between apoptosis and autophagy: molecular mechanisms and therapeutic strategies in cancer. J Cell Death. 2013; 6:37-55.

https://doi.org/10.4137/JCD.S11034 PMID:25278778

49. Jendrossek V, Handrick R, Belka C. Celecoxib activates a novel mitochondrial apoptosis signaling pathway. FASEB J. 2003; 17:1547-49. https://doi.org/10.1096/fj.02-0947fje PMID:12824303

50. Jendrossek V. Targeting apoptosis pathways by Celecoxib in cancer. Cancer Lett. 2013; 332:313-24. https://doi.org/10.1016/i.canlet.2011.01.012 PMID:21345578

51. Chen L, Li G, Peng F, Jie X, Dongye G, Cai K, Feng R, Li B, Zeng $Q$, Lun $K$, Chen J, Xu B. The induction of autophagy against mitochondria-mediated apoptosis in lung cancer cells by a ruthenium (II) imidazole complex. Oncotarget. 2016; 7:80716-34. https://doi.org/10.18632/oncotarget.13032 PMID:27811372

52. Chen L, Meng Y, Guo X, Sheng X, Tai G, Zhang F, Cheng $H$, Zhou Y. Gefitinib enhances human colon cancer cells to TRAIL-induced apoptosis of via autophagy- and JNKmediated death receptors upregulation. Apoptosis. 2016; 21:1291-301. https://doi.org/10.1007/s10495-016-1287-5 PMID:27629794

53. Cao Z, Zhang H, Cai X, Fang W, Chai D, Wen Y, Chen H, Chu F, Zhang Y. Luteolin Promotes Cell Apoptosis by Inducing Autophagy in Hepatocellular Carcinoma. Cell Physiol Biochem. 2017; 43:1803-12. https://doi.org/10.1159/000484066 PMID:29049999 


\section{SUPPLEMENTARY MATERIALS}

\section{Supplementary Tables}

Please browse Full Text version to see the data of Supplementary Tables 1, 2.

Supplementary Table 1. Statistical analysis of celecoxib dose climbing experiment.

Supplementary Table 2. Statistical analysis of chemo-sensitization experiment.

Supplementary Table 3. Statistical analysis of clone formation experiment.

\begin{tabular}{|c|c|c|c|c|c|c|c|c|c|}
\hline \multicolumn{10}{|c|}{$\begin{array}{l}\text { 2wayANOVA } \\
\text { Multiple comparisons }\end{array}$} \\
\hline 1 & $\begin{array}{l}\text { Within each row, compare columns } \\
\text { (simple effects within rows) }\end{array}$ & & & & & & & & \\
\hline \multicolumn{10}{|l|}{2} \\
\hline 3 & Number of families & 2 & & & & & & & \\
\hline 4 & Number of comparisons per family & 6 & & & & & & & \\
\hline 5 & Alpha & 0.05 & & & & & & & \\
\hline \multicolumn{10}{|l|}{6} \\
\hline 7 & Tukey's multiple comparisons test & $\begin{array}{l}\text { Mean } \\
\text { Diff. }\end{array}$ & $95.00 \% \mathrm{Cl}$ of diff. & Significant? & Summary & $\begin{array}{l}\text { Adjusted P } \\
\text { Value }\end{array}$ & & & \\
\hline \multicolumn{10}{|l|}{8} \\
\hline 9 & LN229 & & & & & & & & \\
\hline 10 & DMSO vs. TMZ 250uM & 0.07728 & -0.1011 to 0.2557 & No & ns & 0.6475 & & & \\
\hline 11 & DMSO vs. Celecoxib 30uM & 0.3435 & 0.1651 to 0.5219 & Yes & $* * * *$ & $<0.0001$ & & & \\
\hline 12 & $\begin{array}{c}\text { DMSO vs. Celecoxib } 30 \mathrm{uM}+\mathrm{TMZ} \\
250 \mathrm{uM}\end{array}$ & 0.6027 & 0.4243 to 0.7811 & Yes & $* * * *$ & $<0.0001$ & & & \\
\hline 13 & TMZ 250uM VS. Celecoxib 30uM & 0.2663 & 0.08785 to 0.4447 & Yes & $* *$ & 0.0017 & & & \\
\hline 14 & $\begin{array}{l}\text { TMZ 250uM VS. Celecoxib } \\
\text { 30uM+TMZ 250uM }\end{array}$ & 0.5255 & 0.3471 to 0.7039 & Yes & $* * * *$ & $<0.0001$ & & & \\
\hline 15 & $\begin{array}{c}\text { Celecoxib 30uM vs. Celecoxib } \\
\text { 30uM+TMZ 250uM }\end{array}$ & 0.2592 & 0.08079 to 0.4376 & Yes & $* *$ & 0.0023 & & & \\
\hline \multicolumn{10}{|l|}{16} \\
\hline 17 & LN18 & & & & & & & & \\
\hline 18 & DMSO vs. TMZ 250uM & 0.03566 & -0.1428 to 0.2141 & No & ns & 0.9482 & & & \\
\hline 19 & DMSO vs. Celecoxib 30uM & 0.3534 & 0.175 to 0.5318 & Yes & $* * * *$ & $<0.0001$ & & & \\
\hline 20 & $\begin{array}{c}\text { DMSO vs. Celecoxib } 30 \mathrm{uM}+\mathrm{TMZ} \\
250 \mathrm{uM}\end{array}$ & 0.6174 & 0.439 to 0.7958 & Yes & $* * * *$ & $<0.0001$ & & & \\
\hline 21 & TMZ 250uM vs. Celecoxib 30uM & 0.3178 & 0.1394 to 0.4962 & Yes & $* * *$ & 0.0002 & & & \\
\hline 22 & $\begin{array}{l}\text { TMZ 250uM vs. Celecoxib } \\
\text { 30uM+TMZ 250uM }\end{array}$ & 0.5818 & 0.4034 to 0.7602 & Yes & $* * * *$ & $<0.0001$ & & & \\
\hline 23 & $\begin{array}{c}\text { Celecoxib 30uM vs. Celecoxib } \\
\text { 30uM+TMZ 250uM }\end{array}$ & 0.264 & 0.08559 to 0.4424 & Yes & $* *$ & 0.0018 & & & \\
\hline \multicolumn{10}{|l|}{24} \\
\hline \multicolumn{10}{|l|}{25} \\
\hline 26 & Test details & Mean 1 & Mean 2 & Mean Diff. & SE of diff. & N1 & $\mathrm{N} 2$ & $\mathrm{q}$ & DF \\
\hline \multicolumn{10}{|l|}{27} \\
\hline 28 & LN229 & & & & & & & & \\
\hline 29 & DMSO vs. TMZ 250uM & 1.015 & 0.9378 & 0.07728 & 0.06585 & 5 & 5 & 1.66 & 32 \\
\hline 30 & DMSO vs. Celecoxib 30uM & 1.015 & 0.6715 & 0.3435 & 0.06585 & 5 & 5 & 7.378 & 32 \\
\hline 31 & $\begin{array}{c}\text { DMSO vs. Celecoxib } 30 \mathrm{uM}+\mathrm{TMZ} \\
250 \mathrm{uM}\end{array}$ & 1.015 & 0.4123 & 0.6027 & 0.06585 & 5 & 5 & 12.94 & 32 \\
\hline
\end{tabular}




\begin{tabular}{|c|c|c|c|c|c|c|c|c|c|}
\hline 32 & TMZ 250uM vs. Celecoxib 30uM & 0.9378 & 0.6715 & 0.2663 & 0.06585 & 5 & 5 & 5.718 & 32 \\
\hline 33 & $\begin{array}{l}\text { TMZ 250uM vs. Celecoxib } \\
\text { 30uM+TMZ 250uM }\end{array}$ & 0.9378 & 0.4123 & 0.5255 & 0.06585 & 5 & 5 & 11.29 & 32 \\
\hline \multicolumn{10}{|c|}{ 2wayANOVA } \\
\hline \multicolumn{10}{|c|}{ Multiple comparisons } \\
\hline 34 & $\begin{array}{c}\text { Celecoxib } 30 \mathrm{uM} \text { vs. Celecoxib } \\
\text { 30uM+TMZ 250uM }\end{array}$ & 0.6715 & 0.4123 & 0.2592 & 0.06585 & 5 & 5 & 5.567 & 32 \\
\hline \multicolumn{10}{|l|}{35} \\
\hline 36 & LN18 & & & & & & & & \\
\hline 37 & DMSO vs. TMZ 250uM & 1 & 0.9643 & 0.03566 & 0.06585 & 5 & 5 & 0.7658 & 32 \\
\hline 38 & DMSO vs. Celecoxib 30uM & 1 & 0.6466 & 0.3534 & 0.06585 & 5 & 5 & 7.59 & 32 \\
\hline 39 & $\begin{array}{l}\text { DMSO vs. Celecoxib } 30 \mathrm{uM}+\mathrm{TMZ} \\
250 \mathrm{uM}\end{array}$ & 1 & 0.3826 & 0.6174 & 0.06585 & 5 & 5 & 13.26 & 32 \\
\hline 40 & TMZ 250uM vs. Celecoxib 30uM & 0.9643 & 0.6466 & 0.3178 & 0.06585 & 5 & 5 & 6.824 & 32 \\
\hline 41 & $\begin{array}{l}\text { TMZ 250uM vs. Celecoxib } \\
\text { 30uM+TMZ 250uM }\end{array}$ & 0.9643 & 0.3826 & 0.5818 & 0.06585 & 5 & 5 & 12.49 & 32 \\
\hline 42 & $\begin{array}{c}\text { Celecoxib } 30 \mathrm{uM} \text { vs. Celecoxib } \\
\text { 30uM+TMZ 250uM }\end{array}$ & 0.6466 & 0.3826 & 0.264 & 0.06585 & 5 & 5 & 5.67 & 32 \\
\hline
\end{tabular}

\section{Supplementary Table 4. Statistical analysis of apoptosis experiment.}

\section{2wayANOVA}

Multiple comparisons

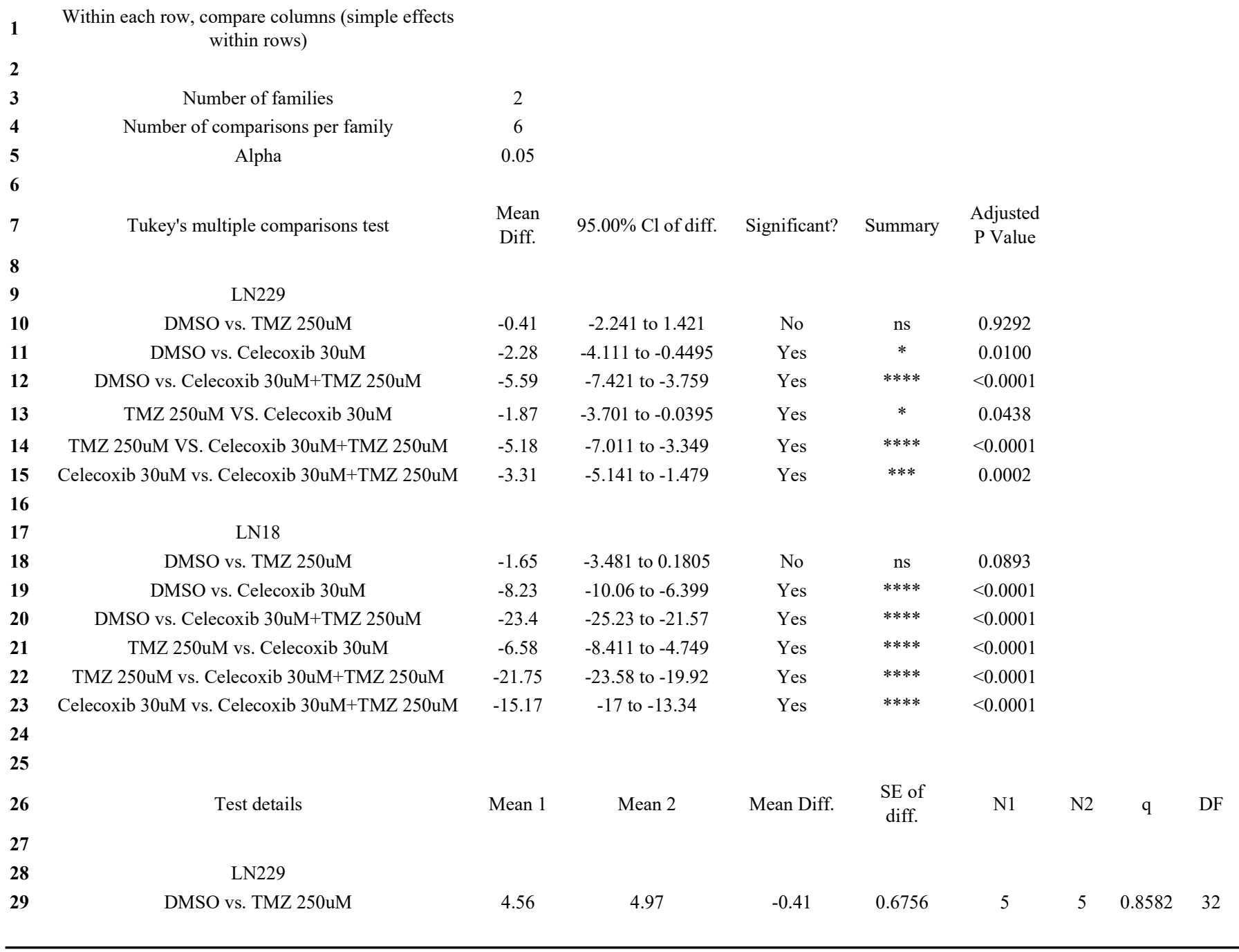




\begin{tabular}{|c|c|c|c|c|c|c|c|c|c|}
\hline 30 & DMSO vs. Celecoxib 30uM & 4.56 & 6.84 & -2.28 & 0.6756 & 5 & 5 & 4.773 & 32 \\
\hline 31 & DMSO vs. Celecoxib 30uM+TMZ 250uM & 4.56 & 10.15 & -5.59 & 0.6756 & 5 & 5 & 11.7 & 32 \\
\hline 32 & TMZ 250uM vs. Celecoxib 30uM & 4.97 & 6.84 & -1.87 & 0.6756 & 5 & 5 & 3.914 & 32 \\
\hline 33 & TMZ 250uM vs. Celecoxib 30uM+TMZ 250uM & 4.97 & 10.15 & -5.18 & 0.6756 & 5 & 5 & 10.84 & 32 \\
\hline \multicolumn{10}{|c|}{$\begin{array}{l}\text { 2wayANOVA } \\
\text { Multiple comparisons }\end{array}$} \\
\hline 34 & Celecoxib 30uM vs. Celecoxib 30uM+TMZ 250uM & 6.84 & 10.15 & -3.31 & 0.6756 & 5 & 5 & 6.929 & 32 \\
\hline 36 & LN18 & & & & & & & & \\
\hline 37 & DMSO vs. TMZ 250uM & 6.44 & 8.09 & -1.65 & 0.6756 & 5 & 5 & 3.454 & 32 \\
\hline 38 & DMSO vs. Celecoxib 30uM & 6.44 & 14.67 & -8.23 & 0.6756 & 5 & 5 & 17.23 & 32 \\
\hline 39 & DMSO vs. Celecoxib 30uM+TMZ 250uM & 6.44 & 29.84 & -23.4 & 0.6756 & 5 & 5 & 48.98 & 32 \\
\hline 40 & TMZ 250uM vs. Celecoxib 30uM & 8.09 & 14.67 & -6.58 & 0.6756 & 5 & 5 & 13.77 & 32 \\
\hline
\end{tabular}

